\title{
Integrating Micro-credentials into Professional Learning: Lessons from Five Districts
}

By Christina Luke and Viki M. Young

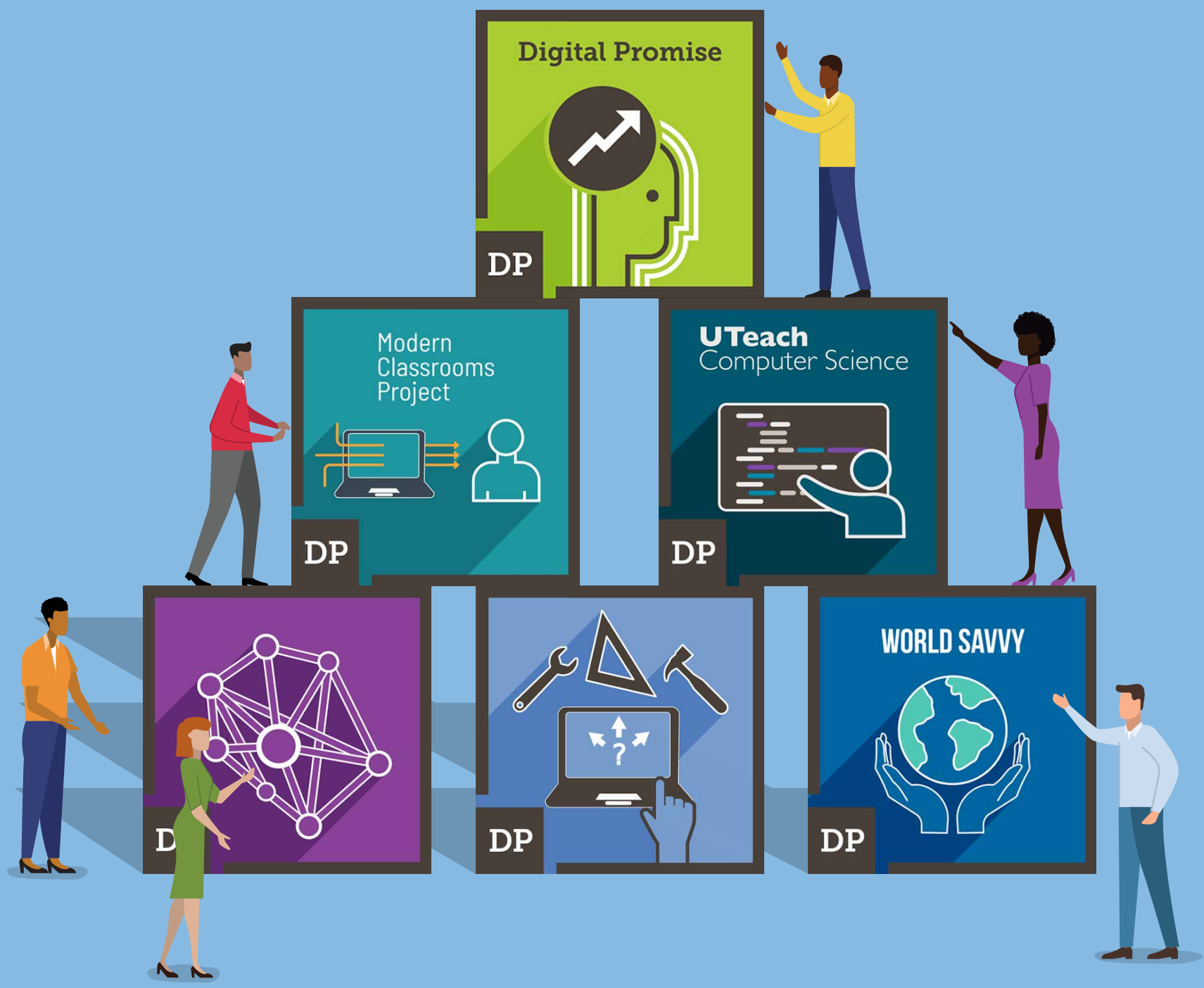

Digital Promise 


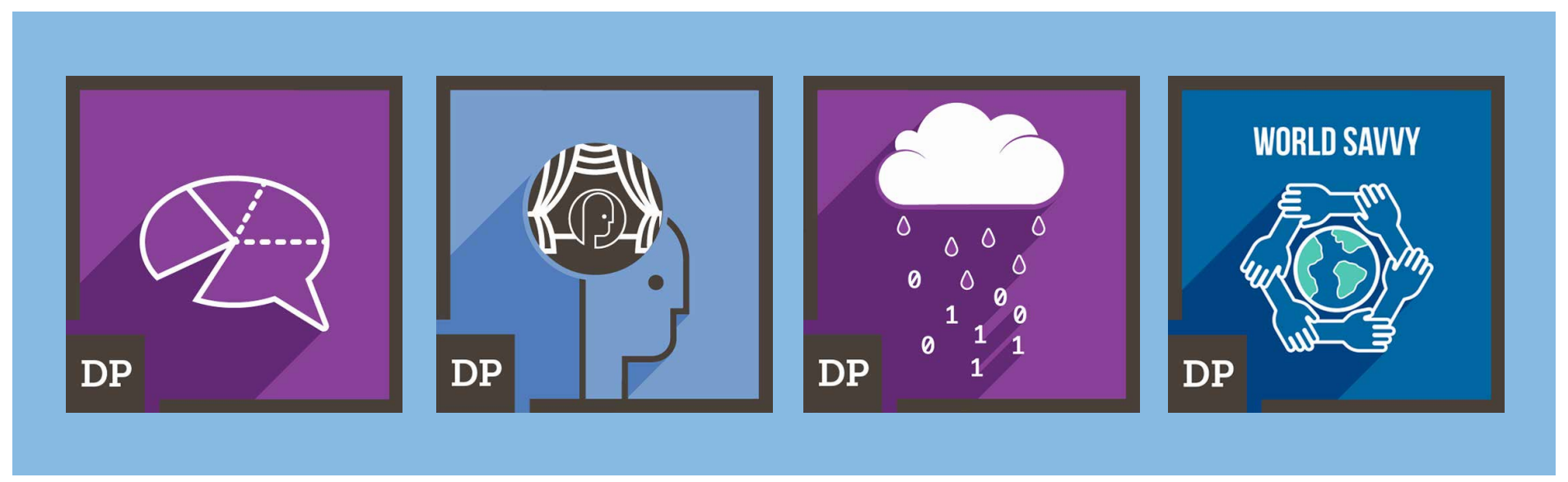

\section{Table of Contents}

1. Integrating Micro-credentials Effectively. . . . . . . . . . . . . . 3

2. Deepening Learning Through Micro-credentials . . . . . . . . . . . . . 5

3. Strategies Facilitating Learning Through Micro-credentials . . . . . . . . . . . 7

4. Sustaining and Expanding the Role of Micro-credentials in Professional Learning . . . . . . . . . . . . . . . . . . . . . 9

5. Evolving Policies for Micro-credential Integration . . . . . . . . . . . 11

Acknowledgements . . . . . . . . . . . . . . . . . . 13 
Educator micro-credentials present a unique opportunity to link professional learning to practice. Through each competency-based credential, educators demonstrate application of their learning. School districts are seeing the value of embedding micro-credentials in existing professional learning pathways to promote educator agency, recognize educators developing their practice, and expand competency-based learning practices with students.

Micro-credentials are particularly well-suited for introducing emerging technologies and content. Offering greater flexibility than one-time, standand-deliver professional learning, micro-credentials can serve as a vehicle for just-in-time, embedded learning in high-demand areas like computational thinking. While learning opportunities in computational thinking may have once been limited for educators without close proximity to a university with computer science education pathways, through micro-credentials, researchbased resources are curated and made accessible to educators with an internet connection. ${ }^{1}$

This paper captures experiences and insights from educators and administrators as their districts integrated micro-credentials in support of professional learning. Learnings include suggestions for integrating micro-credentials effectively, ideas for deepening learning through micro-credentials, strategies for facilitating learning through micro-credentials, approaches to sustaining and expanding the role of micro-credentials for professional learning, and insights on evolving policies for micro-credential integration.

In the fall of 2018, League of Innovative Schools district leaders were invited to apply to participate in a Computational Thinking for Next Generation Science Standards (NGSS) Challenge Collaborative to answer the question: How might we support effective, inclusive NGSS implementation through professional learning, computational thinking, and micro-credentials? Five school districts were selected to participate in a two-year effort to:

- Develop engaging, high-impact professional learning experiences for educators focused on NGSS instruction;

- Improve engagement and inclusion of female and Black and Latinx students in science instruction through computational thinking;

- Develop and publish high-quality professional development and instructional materials on computational thinking in NGSS; and

- Pilot and revise 10 micro-credentials on computational thinking competencies. 
Districts used the framing of a problem of practice to identify systemic improvements in professional learning for computational thinking. Through this collaborative, data were captured from participating district leaders and educators. The surveys, interviews, and focus groups revealed valuable guidance for school districts interested in formally embedding micro-credentials in their professional learning pathways.

District Profiles. Early in the Challenge Collaborative, district representatives were asked to share their motivations and goals for introducing micro-credentials. From their perspectives, there were five compelling reasons to pursue competency-based professional learning:

1. Promote educator agency in professional learning initiatives;

2. Promote educator self-efficacy;

3. Identify educators that have demonstrated specific skills, particularly in emerging areas;

4. Formally recognize and reward educators; and

5. Gain insights into the application of professional learning in practice.

The school districts were all members of the League of Innovative Schools but varied significantly in their size, geography, urbanicity, and student demographics (see Table 1. District Demographics).

Table 1. District Demographics

\begin{tabular}{|l|l|l|r|r|r|}
\hline District & $\begin{array}{l}\text { Approximate } \\
\text { Student } \\
\text { Enrollment }\end{array}$ & Urbanicity & $\begin{array}{r}\text { Percent of } \\
\text { Students } \\
\text { Experiencing } \\
\text { Poverty }\end{array}$ & $\begin{array}{r}\text { Percent of } \\
\text { Students } \\
\text { Identifying as } \\
\text { Latinx }\end{array}$ & $\begin{array}{r}\text { Percent of } \\
\text { Students } \\
\text { Identifying as } \\
\text { Black }\end{array}$ \\
\hline Broward, FL & 268,000 & Urban & $66 \%$ & $36 \%$ & $40 \%$ \\
\hline Vancouver, WA & 23,400 & Suburban & $48 \%$ & $27 \%$ & $3 \%$ \\
\hline Compton, CA & 23,000 & Urban & $83 \%$ & $79 \%$ & $18 \%$ \\
\hline lowa City, IA & 14,000 & Suburban & $37 \%$ & $12 \%$ & $19 \%$ \\
\hline Talladega, AL & 7,500 & Rural & $71 \%$ & $2 \%$ & $33 \%$ \\
\hline
\end{tabular}

Through the Challenge Collaborative, participating school districts uncovered valuable insights about effectively integrating micro-credentials, engaging educators and supporting their learning, and planning for sustainability. These learnings are each explored in greater detail throughout this paper. 


\section{Integrating Micro-credentials Effectively}

Introducing a new element to an existing professional learning system can be jarring for educators if they are not involved in the development and decision. District administrators learned that to effectively embed micro-credentials, they needed to do two things: 1) build awareness of micro-credentials, and 2) encourage educator buy-in.

Building Awareness. While micro-credentials show great promise for shifting to competency-based professional learning, their use is still limited. Participating districts encouraged sharing the following information with staff when building awareness about micro-credentials within a school system:

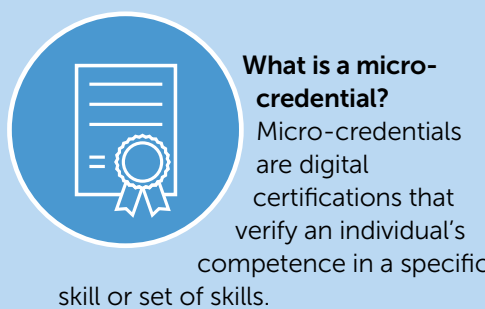

skill or set of skills.

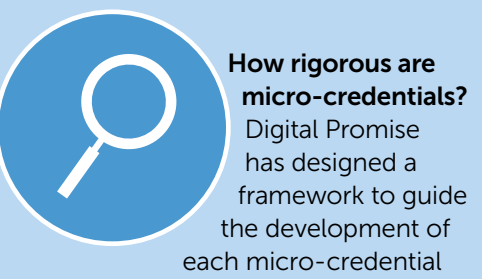

to ensure its rigor. This framework guarantees that each micro-credential focuses on a single competency, has a key method that is backed by research requires the submission of evidence, and includes a rubric or scoring guide.

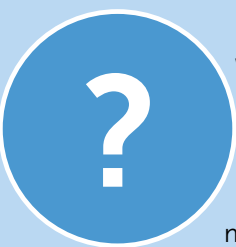

Why have other districts implemented micro-credentials? School districts have chosen to embed micro-credentials for a number of reasons, Micro-credential Platform are Open Badges. Open Badges are verifiable, portable, and controllable. credentials shared? All microcredentials earned on the Digital Promise including to improve educator retention by supporting their agency in what they learn and when; to verify

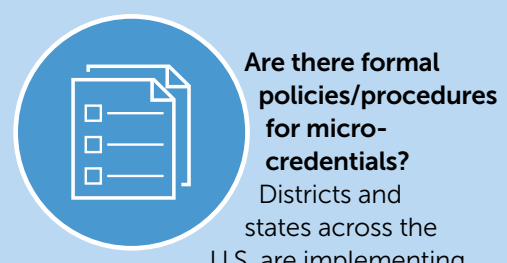

formal recognition policies for micro-credentials. More details can be found on Digital Promise's State Policy Map.

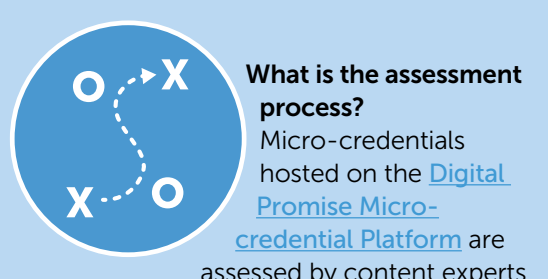

assessed by content experts using rubrics that have undergone validity and reliability testing. If a submission does not meet criteria, feedback is provided to the earner so they can modify and resubmit. The process is double-blind, so neither the earner nor the assessor can identify one another.

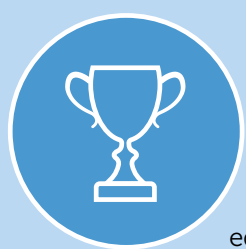

What types of incentives have been offered to earn micro-credentials?

Districts often offer educators career ladder educators' demonstrated skills; to offer skill-based recognition and rewards; to ensure students' powerful learning experiences in emerging content areas; and to shift to competencybased credit toward recertification and salary advancement.

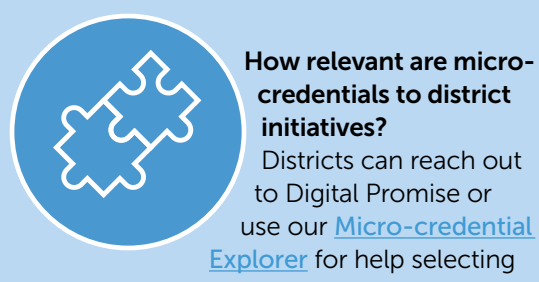

from hundreds of existing micro-

credentials that align to current district initiatives or districts may choose to develop their own micro-credentials. 
Encouraging Educator Buy-in. In addition to building awareness of micro-credentials among staff, districts also needed to consider how they would encourage educator engagement with a new professional learning feature. Each participating district offered one or more of the following incentives to educators to pursue and earn micro-credentials:

- Planning and collaboration time to prepare micro-credential submission

- Stipend for time spent preparing micro-credential submission

- Stipend for earning each micro-credential

- Leadership opportunities for those who have earned micro-credentials

- Hours or credit toward recertification

Districts used different approaches to integrating, incentivizing, and supporting micro-credentials. While some districts offered opportunities for all educators to earn micro-credentials, others piloted micro-credentials with a selected group. In all cases, incentives and supports were offered to educators, and in some cases those incentives were formally connected to existing professional learning systems (e.g., planning time to collaborate).

Offering clear communication about the purpose and value of pursuing micro-credentials and offering tangible support to educators were keys to successfully implementing micro-credentials in a district context.

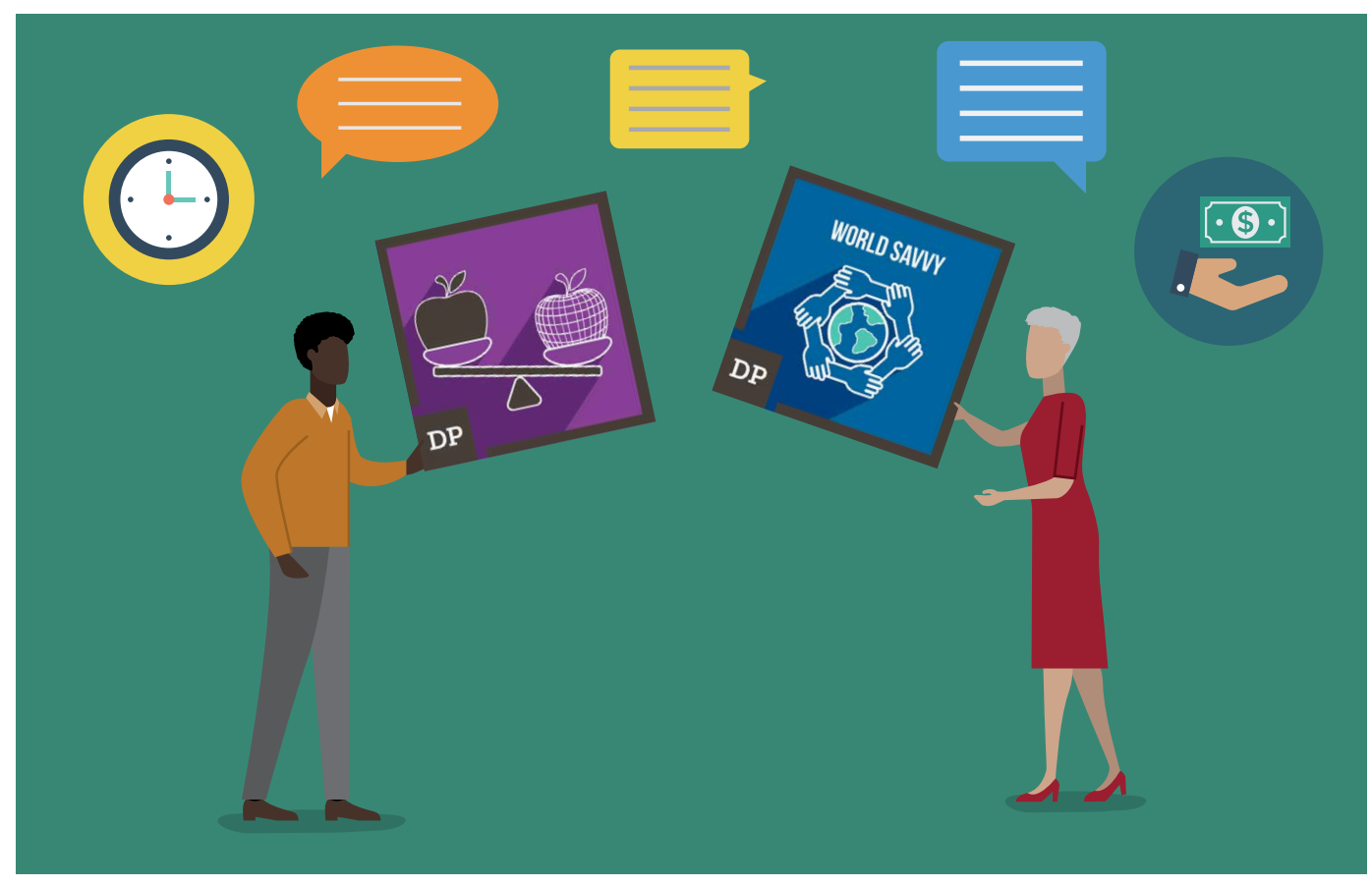




\section{Deepening Learning Through Micro-credentials}

In addition to exploring district implementation, data gathered from this project shed light on educators' experiences with learning new content with micro-credentials. Overall, participating educators responded positively to the learning opportunities presented by pursuing computational thinking micro-credentials. Approximately three-quarters (73 percent) of participating teachers surveyed reported that they could clearly articulate the purpose of micro-credentials to a colleague, indicating the teachers' understanding of micro-credentials (Figure 2). A large majority (84 percent) agreed that completing micro-credentials was significant to their learning about computational thinking, and approximately three-quarters (76 percent) would recommend Digital Promise micro-credentials to colleagues.

Figure 2. Teachers' Receptivity to Micro-credentials

Based on my experience, I would recommend Digital Promise micro-credentials to colleagues for computational thinking and beyond

I can clearly articulate the purpose of microcredentials to a colleague

Completing micro-credentials was a significant part of my learning about computational thinking

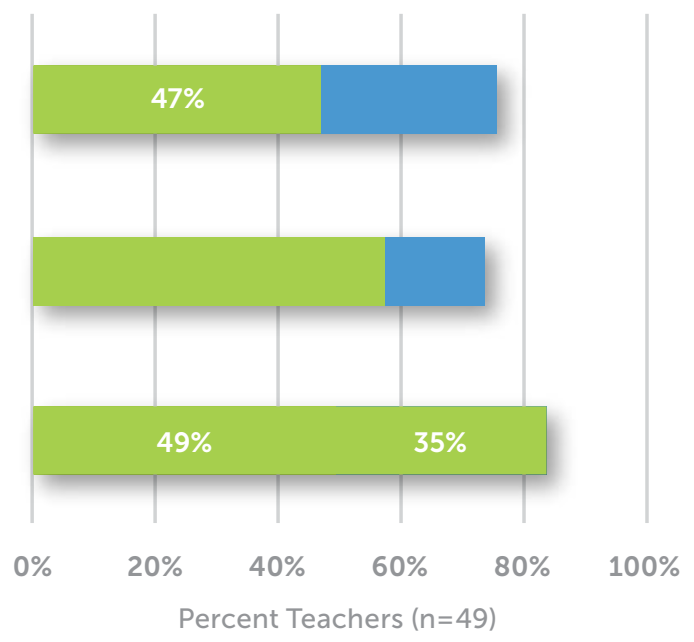

- Agree Strongly Agree

\section{Focusing on Integrating New Learning into Instructional Practice}

Teachers indicated that completing the micro-credential helped them target computational thinking practices in their lessons.
"[T]he tendency is to focus on your content, and computational thinking is more of a practice. So, [the micro-credential] helped me to really focus within my NGSSa standard how I was going to make sure that Imy students] were practicing computational thinking skills."

- Teacher 
"We were doing computational thinkingrelated activities in [our] curriculum, but the micro-credential gave me a little more background knowledge and the importance of why to integrate CT into the curriculum and gave me a little bit more focus on the integration of CT in the lessons that I had Another teacher explained how the micro-credentials helped her emphasize computational thinking (CT) with her existing curriculum. previously done."

- Teacher

The micro-credential process also supported teachers' efforts to deepen their practice in multiple ways, through reflection, challenge, and choice, as the following teachers explained:

"[Completing the micro-credential] also offered me a challenge: How can I take what we are already doing and it make better, how to integrate technology, how can I know how I am doing as a teacher with mastering the skill in the classroom, and how can I improve the next time."

- Teacher

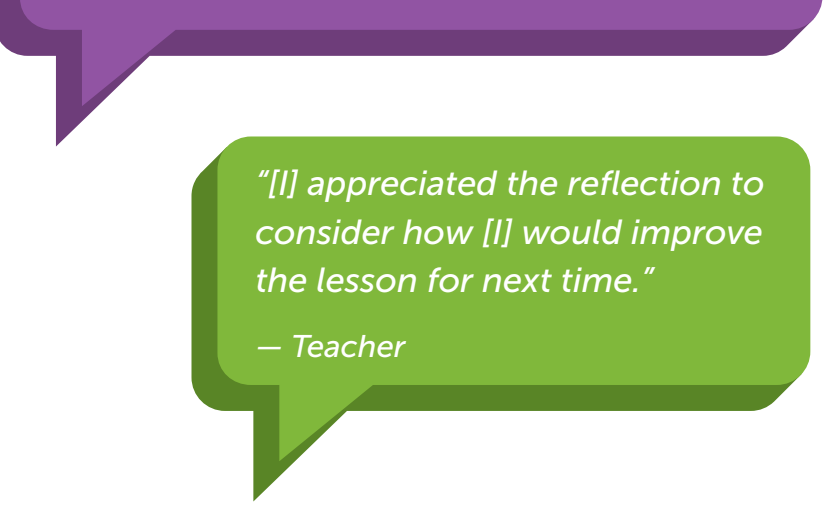

"[W]ith micro-credentials it was different because [they] allow you to develop at your own pace. And they also allow you to delve deep into things that you may not feel as confident with and areas that you feel like you really need to improve."

- Teacher 


\section{Strategies Facilitating Learning Through Micro-credentials}

As districts implemented various strategies to embed micro-credentials in their professional learning program, teachers identified the key experiences that were instrumental to their learning as they completed their micro-credentials.

Implementing a Cohort Model. Like all learning, professional learning is a social endeavor, where teachers can share problems of practice, questions, experiences, and insights. Teachers who pursued their computational thinking micro-credentials in peer cohorts pointed to this collaboration as integral to their learning. Among participating teachers surveyed, collaborative planning time with colleagues was the top support, cited by roughly three-quarters (74 percent) of the respondents. "A lot of us created relationships and worked with different teachers from different schools to be able to implement [micro-credentials]," explained one teacher. Working together on specific micro-credentials provided teachers with opportunities to share with each other instructional activities and tools they used: "Some of those teachers shared other resources that I haven't used before, which I'm looking forward to implementing, [such as] apps and websites where students can create games," another teacher said.

District leaders also saw that providing teachers with the opportunity to pursue the professional learning together strengthened their integration of computational thinking in the classroom and work for the micro-credentials with peer feedback:
"The way we approached [micro-credentials] through the PLC (professional learning community) concept, where a group of teachers were working together toward the same [micro-credential], added support and really helped them so they weren't alone. They were able to review each other's [work] and give each other feedback"

- District Leader

Providing Ongoing Support. Also building on attributes of high-quality professional development, ongoing support during the school year and the period during which teachers worked on their micro-credentials ensured that their learning was sustained, coherent, and less episodic. The highest proportion of teachers surveyed (54 percent) cited computational thinking professional development as one of the top three supports in integrating computational thinking into their lessons. District leaders met with teacher cohorts at least three or four times in person during the school year, and some held monthly virtual meetings. One district used a series of ongoing supports to explicitly guide teachers through the micro-credential process: "Having learning opportunities at the beginning, the ongoing virtual support class, and then coming together to write and submit the micro-credentialswalking [teachers] through that process and having that support along the way contributed to our success this year," a leader in the district explained. 
Across districts, these meetings provided teachers the time to discuss instructional activities related to the micro-credential and to complete the micro-credential application. "The best things as a district [was] the time to plan," said one teacher. Another said this time was valuable "just to discuss different ways to tackle each micro-credential and share ideas." Having a structure for ongoing support can also help teachers in planning classroom activities that could be submitted as artifacts for a micro-credential: "If I'm going to do micro-credentials, I really need to plan ahead and have students [produce] the tools and artifacts," one teacher said. Districts offering supports throughout the year recognize teachers' need for sustained professional learning opportunities.

To facilitate learning and completion of micro-credentials, districts supported teachers' work on the micro-credentials during the school day. By doing so, district leaders signalled respect for teachers' time and the importance they placed on the experience for teachers' learning. The scheduled time ensured that the full cohort could meet the expectation that each teacher complete two micro-credentials. Providing time during the work day lowered a typical barrier-that collective bargaining agreements may not have provisions for teachers to spend time on micro-credentials above the defined staff meetings, professional development (PD) requirements, and prep times.

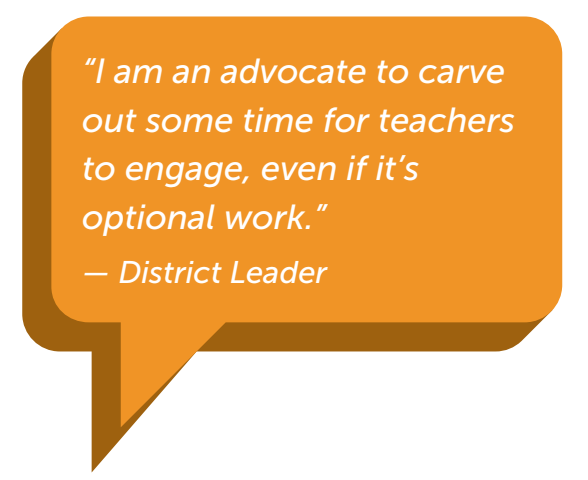

Thus, repurposing some of the agreed-upon staff meeting or PD time makes it feasible for districts to integrate micro-credentials into their professional learning strategies.

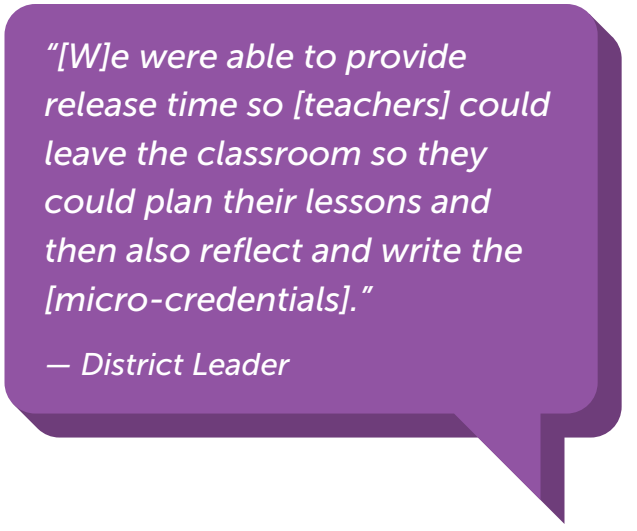

Offering Content-Specific Tools and Resources. Content specificity is also a pillar of effective professional development. ${ }^{2}$ The micro-credentials provided tools and resources grounded in computational thinking and helped teachers learn to integrate the tools with their instructional units. A significant proportion of teachers surveyed responded that specific pedagogical resources for teaching computational thinking (e.g., look-fors, lesson plans, student resources) (32 percent) and resources for defining computational thinking (e.g., articles) (28 percent) were among the top three strategies supporting computational thinking implementation in the classroom. 
To deepen their understanding of computational thinking and to integrate it into their instruction, teachers reported that additional time, professional development, and resources (e.g., curriculum, tools, example lesson) would be helpful. "We've held many district-level meetings, and during those meetings they provide us with... a list of resources that would be beneficial, and we get to kind of use that time to play with them." Additionally, the feedback teachers received when resubmitting or earning a micro-credential had a powerful impact on their practice because it either provided suggested modifications or validated they were on the right track. In other examples, one teacher requested labdiscs to test and collect data on dissolved oxygen and also used her own supply of micro:bits to teach students to write simple programs. Another teacher incorporated into her daily routine a graph resource she received from the professional development: "I think it builds the capacity for students to start seeing the visuals of data and then...question where that data came from," she said. Teachers seeking resources for instructional activities suggested that "some more time in PD or [someone] to spend time curating resources for graphing and data would be helpful," or even simply "a newsletter highlighting tools or strategies [to bring] into your classroom" could be supportive.

\section{Sustaining and Expanding the Role of Micro-credentials in Professional Learning}

Understanding how districts might embed micro-credentials into their professional learning strategies was an explicit goal of the Computational Thinking for NGSS Challenge Collaborative. Participating districts gained several key lessons that we share here to spotlight how others might launch, sustain, and expand the role of micro-credentials in teacher professional learning.

Building Robust Incentive Structures. District leaders indicated that to sustain micro-credentials as part of their professional learning strategy, explicit incentives would be important. Incentives for teachers to pursue micro-credentials can range from financial and official endorsements to intangibles such as peer respect and acknowledgement of their expertise, and intrinsic rewards such as a sense of accomplishment. More than 90 percent of teachers surveyed reported that monetary bonuses and stipends for time spent would be "definitely motivating" or "very motivating" in completing another micro-credential. A majority of teachers also reported that professional growth opportunities (71 percent) and having dedicated time to work on the micro-credential (76 percent) would be "definitely" or "very motivating."

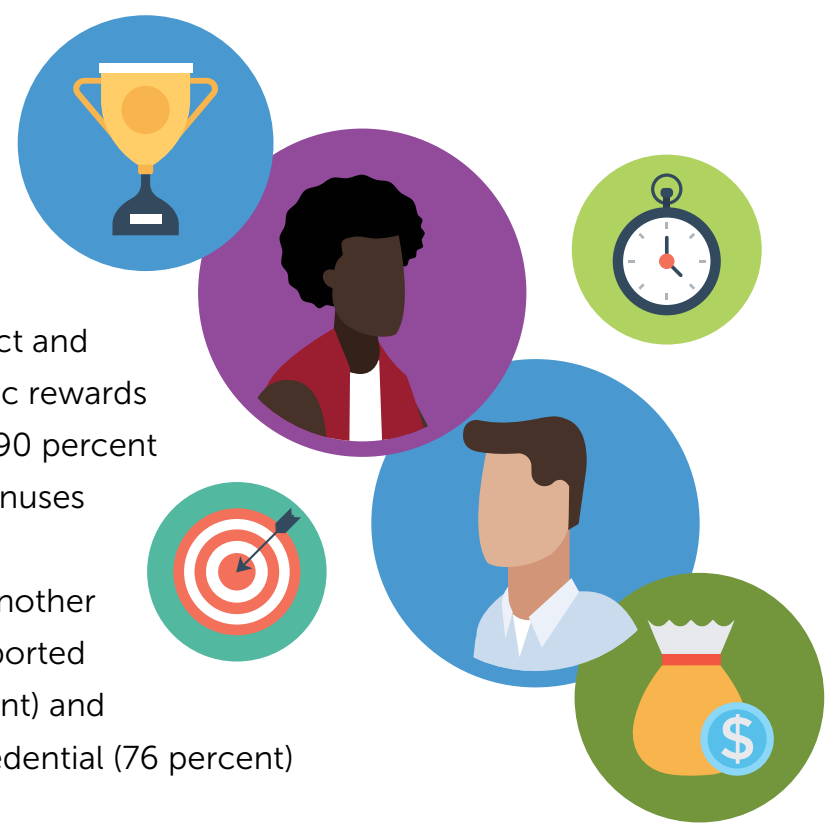


Another way to create time for micro-credentials and incentivize teachers would be to designate micro-credentials as eligible for meeting the "state's clock hour requirement for continuing education," one district leader suggested. Relatedly, a majority of teachers (71 percent) responded that it would be motivating if micro-credentials contributed to the requirements they needed to advance on or were connected in some way to the district's career ladder and salary schedule. Teacher incentives will continue to be central, especially as districts indicated that micro-credentials would remain voluntary without changes to the local collective bargaining agreement in some cases. Incentives thus need to be significant enough to draw teachers' attention to micro-credentials and be strong enough to change habits of following traditional professional development offerings.

Identifying and Developing Micro-credentials Tied to District Outcomes. As with other district professional learning strategies, tying micro-credentials to district goals will help

"[Micro-credentials] allow us to track

the effectiveness of our PD. We need to

develop [micro-credentials] that are tied

to our district outcomes and goals as

determined by data.

- District Leader target teacher time and other district

resources toward the meaningful

outcomes the district has identified

for student learning and achievement.

Moreover, aligning micro-credentials

to district goals will provide teachers

with coherence in their professional

learning experiences. This will allow

teachers to build

their exper-

tise across professional learning opportunities, rather than participating in disparate PD activities that fragment their time, attention, and efforts. From a district perspective, leaders want to ensure that the professional learning they offer is a worthwhile investment.

Because micro-credentials are competency- and research-based, district leaders would have a better sense that the professional learning they provide encourages teachers to try new practices and master skills grounded in evidence. Said a leader from another district: "The district is interested in documenting and leveraging individuals that are actually implementing practices, not just [sitting] through a training."

\section{Redesigning District Professional Learning Systems to Integrate Micro-credentials.}

To use micro-credentials as a lever in meeting district instructional goals, districts began thinking about redesigning their professional learning strategy to integrate micro-credentials. Doing so allows district leaders to prioritize micro-credentials that align with district goals and to build supports for teachers to pursue them, such as the cohort model and other strategies discussed above. For example, one district leader specified that their district is "planning to use micro-credentials for PD for computational thinking as well as equity. Equity micro-credentials are global cultural competence. Anti-bias instruction helps 
students develop intercultural competence....They are aligned with and built on those focus areas that the district had already implemented."

Depending on their contexts, districts may need to make other changes to facilitate greater use of micro-credentials; for example renegotiating local collective bargaining agreements and developing school leader buy-in and understanding to commit PD time for supporting teachers' micro-credential work may be necessary.

Offering Endorsements. Additional policies that provide external and authentic validation for earning micro-credentials can further motivate some teachers. Micro-credentials by definition signal the holder's mastery of competencies meaningful to instruction, as supported by research. Public identification of a teacher's earned micro-credential and endorsement on their teaching certificate can signal the value of specific competencies and the value of competency-based learning more broadly. The transparency of who holds which micro-credentials can support district and school decision making in identifying teachers as master teachers and resources to support colleagues in integrating into instruction specific skills and knowledge for which they earned a micro-credential. "[W]e would like to award a credential to teachers that have completed professional learning," said a district leader. "They need a 'What's in it for me?' What does it lead to?' I think the endorsement might do that-the endorsement might lead to better jobs, a career ladder." In this way, micro-credentials can contribute to a policy focus that recognizes and rewards teachers' demonstrated professional expertise.

\section{Evolving Policies for Micro-credential Integration}

Currently, the COVID-19 pandemic has created a need for flexible and relevant online professional learning. Micro-credentials help educators demonstrate their proficiency in rigorous, research-based content and receive recognition for their skills in an online environment. This flexibility is essential as educators and their students navigate unpredictable schedules, learning models, and health concerns. With the COVID-19 pandemic, many schools are transitioning to hybrid or fully remote learning models for students which can

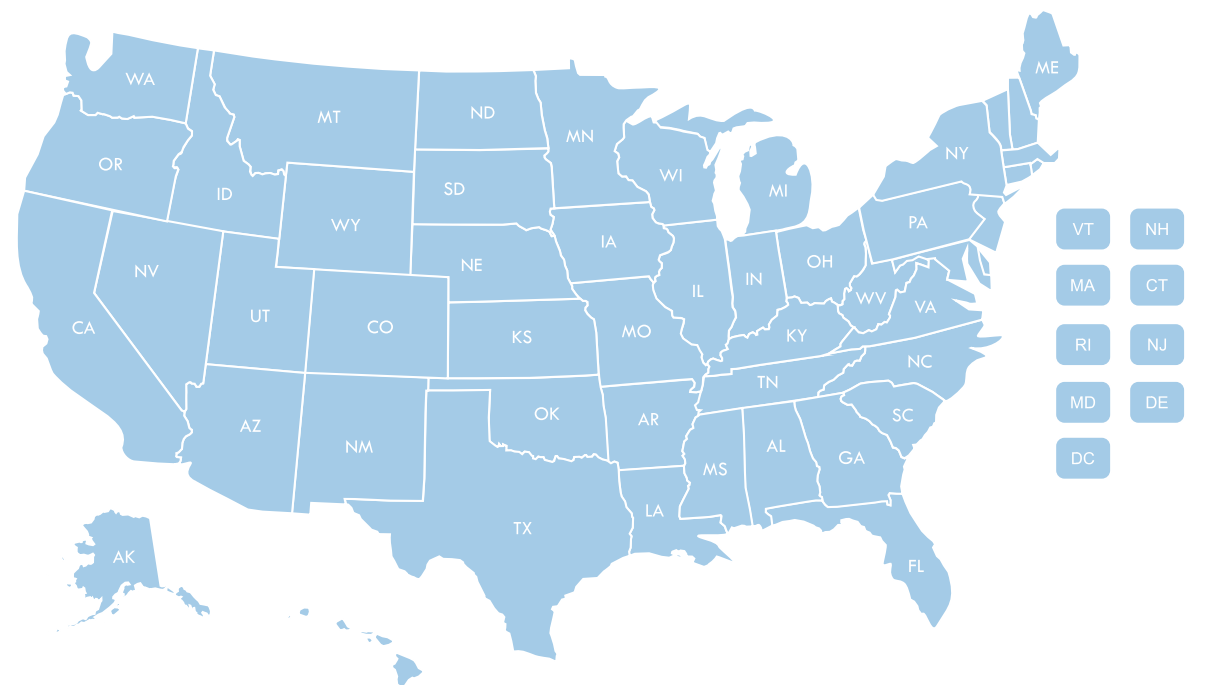

Visit the Micro-credential Policy Map 
benefit from competency-based learning experiences. Allowing students to have agency as learners and demonstrate their skills and competencies through multiple mechanisms creates greater equity in assessment. For remote learners, digital badging presents an opportunity to keep track of achievements representing the successful application of learning. And at a time when professional learning must be delivered differently, providing the same opportunities for educators to engage with competency-based learning through micro-credentials solves for distance learning and accountability simultaneously.

District professional learning policies are situated in broader state and national policy landscapes. Even before COVID-19, states and districts were increasingly formally recognizing micro-credentials for advancement, recertification, and endorsement. Particularly in emerging content areas like computer science and computational thinking, states are exploring micro-credential pathways to certification. And micro-credentials in topic areas like transitioning to digital learning, social-emotional learning, and culturally responsive teaching practices have recently gained popularity as educators seek to create hybrid and remote learning environments that are also culturally affirming.

As districts and states develop policies that formally recognize micro-credentials, they must ensure the quality of micro-credential content, implementation, and assessment. The Design, Assessment, and Implementation Principles for Educator Micro-credentials published by CCSSO and developed by a coalition of education organizations earlier this year provides guidance for policy development. Finally, districts can draw upon learnings from this paper as they move to formally integrate micro-credentials into professional learning:

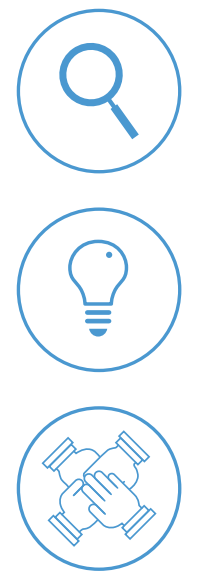

Integrate micro-credentials effectively by building awareness and encouraging buy-in;

Deepen learning through micro-credentials by focusing on integrating new learning into instructional practice;

Facilitate learning through micro-credentials by intentionally creating collaboration opportunities such as a cohort model, providing ongoing support, and offering content-specific resources and tools; and

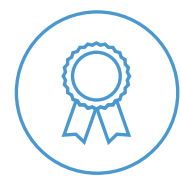

Sustain and expand the role of micro-credentials for professional learning by building robust incentive structures, identifying and developing micro-credentials tied to district outcomes, redesigning professional learning systems to integrate micro-credentials, and offering endorsements. 


\section{Acknowledgements}

The research that grounded this publication would not have been possible without the contributions of educators and administrators from Broward County Public Schools, FL; Vancouver Public Schools, WA; Compton Unified School District, CA; lowa City Community School District, IA; and Talladega County Schools, AL. The research was led by Dr. Kelly Mills with support from Dr. Quinn Burke, Dr. Pati Ruiz, and Dr. Viki M. Young. Special thanks to the project team, especially Jeffrey Fett, Elyse Gainor, Maria Romero, Josh Weisgrau, and Odelia Younge, as well as Jessica Schuler and the Digital Promise Communications, Learning Experience Design, and Micro-credentials teams. 